\title{
Featured issue: Lead-free solder and packaging
}

\author{
Arthur Willoughby
}

Published online: 15 December 2011

(C) Springer Science+Business Media, LLC 2011

In the first two issues of 2012 we are highlighting fields which are topics of particular current interest in our discipline. The first of these is 'Lead-free solder and packaging'. Since the Special Issue published in this journal in 2007 (J. Mater. Sci: Mater. Electron 18:1-365, 2007) on 'Lead-Free Electronic Solders' which was ably edited by our colleague and Guest Editor, Professor K.N. Subramanian, this and other journals have received many papers on this subject, which is vital to our field. As Prof. Subramanian pointed out, in his Preface to that issue,

Leaching of toxic lead from electronic wastes can result in contamination of the human food chain causing serious health hazards. As a consequence, several European and Pacific Rim countries have passed legislations warranting elimination of lead from electronic solders by fast approaching deadlines.
Global economic pressures brought on by such legislations have resulted in a flurry of research activities to find suitable lead-free substitutes for the traditional leaded electronic solders.

The research activities in this field are still high, despite the original deadlines having passed for some of these requirements. This has led us to create a 'Virtual Issue' on this subject recently, from published papers on this topic (springeralerts@springer.delivery.net-which is free for downloading), and has led to this Featured Issue from papers submitted as regular submissions. The issue includes not only papers on metallic solders, but also non-metallic joining and bonding, and issues important to packaging of electronic and optoelectronic components. We hope that you will find this issue of interest, and that it will help to stimulate further research on this important topic.

A. Willoughby $(\bowtie)$

Southampton, UK

e-mail: A.F.Willoughby@ soton.ac.uk 